\title{
Ensino de Geografia e cenários urbanos cotidianos: laboratórios para o desenvolvimento do pensamento geográfico
}

Lana de Souza Cavalcanti

Universidade Federal de Goiás, Brasil.

Recibido: 14 de noviembre de 2017. Aceptado: 23 de julio de 2018.

\begin{abstract}
Resumo
A cidade é uma espacialidade complexa, cuja compreensão tem sido buscada por vários estudiosos, entre eles os geógrafos. Como ensiná-la? Como ensiná-la a jovens escolares tendo como referência sua vida e seus significados? O texto busca, com essas preocupações, abordar caminhos possíveis para o ensino de cidade tendo em vista sua relação com a vida cotidiana, com a contribuição da Geografia urbana. Para desenvolver essa abordagem, utiliza-se de cenários urbanos -fragmento da vida cotidiana- para serem problematizados no ensino, buscando apresentar chaves da leitura de imagens e textos a partir de eixos analíticos e de conceitos e subconceitos, compreendidos como um sistema conceitual estruturante do conceito mais amplo de cidade. O texto busca ainda articular essas possibilidades de leitura com o cotidiano dos jovens e com a relação que têm com os lugares, as paisagens e os territórios da cidade, com base em investigações realizadas. Ao final, o texto apresenta também breves considerações sobre as possiblidades de tratar esses fragmentos da vida urbana cotidiana, como conteúdos geográficos escolares relevantes para jovens escolares, com a meta de seu desenvolvimento conceitual.
\end{abstract}

PALAVRAS-CHAVE: ENSINO DE GEOGRAFIA. CIDADE. VIDA COTIDIANA. CENÁRIOS URBANOS. JOVENS ESCOLARES.

\section{Teaching Geography and everyday urban scenarios: laboratories for the development of geographic thought}

\begin{abstract}
The city is a complex spatiality, whose understanding has been sought by several scholars, among them, the geographers. How to teach it? How to teach it to young students with reference to their lives and their meanings? The text seeks, with these concerns, to address possible ways to teach the city in view of its relationship with daily life, with the contribution of urban Geography. To develop this approach, urban scenarios -a fragment of daily life- are used to be problematized in the teaching process, seeking to present keys to read images and texts from analytical axes, concepts and sub-concepts,
\end{abstract}


understood as a conceptual system structuring the concept of the city. The text also seeks to articulate these reading possibilities with the daily life of young people and their relationship to places, landscapes and territories of the city, based on investigations carried out. In the end, the text also presents brief considerations about the possibilities of treating these fragments of everyday urban life as relevant geographic contents for young students, aiming for their conceptual development.

KEY WORDS: TEACHING GEOGRAPHY. CITY. DAILY LIFE. URBAN SCENARIOS. SCHOOL YOUNG

PALABRAS CLAVE: ENSEÑANZA DE GEOGRAFÍA. CIUDAD. VIDA COTIDIANA. ESCENARIOS URBANOS. JÓVENES ESCOLARES.

\section{Cidade e vida urbana cotidiana: conceitos para o ensino de geografia}

A proposição deste artigo é colocar, lado a lado, dois conceitos, cidade e vida urbana cotidiana, desenvolvendo possibilidades analíticas pelo campo da Geografia. Para isso, algumas questões podem ser apresentadas inicialmente: Qual a relação entre eles? Até que ponto a cidade expressa a vida urbana que nela habita? Como ela expressa a vida que acontece em suas ruas, casas, construções? Como a Geografia analisa a dinâmica da vida urbana considerando a escala do lugar e a dimensão do cotidiano? Esses conceitos são importantes para compreender e ensinar as cidades latino-americanas no contexto contemporâneo? Como eles podem ser sistematizados como orientações para seu ensino?

Os estudiosos da cidade, ao buscarem sua origem na história, têm várias explicações para o início desse tipo de organização/produção espacial. Frequentemente associada ao resultado da divisão do trabalho social ao longo do tempo histórico, a cidade é identificada como lugar de uma parcela da sociedade, dedicada a tipos específicos de atividades, propiciada pelo avanço nos modos de relação e de controle dos homens entre si e dos homens frente aos recursos da natureza. Ao longo da história, portanto, as cidades, sejam grandes ou pequenas, se consolidaram como espaço de um modo de vida, reunindo pessoas que vivem coletivamente, dedicando-se à indústria, ao comércio, à administração da vida dos grupos sociais. No presente momento, com o tão destacado fenômeno da globalização propiciado pelo avanço tecnológico na produção de materiais, e no tema da informação e comunicação em particular, há um nível de padronização dessa vida social, tornando assim muitas cidades semelhantes em sua dinâmica interna, em suas paisagens e na lógica de seu funcionamento, o que permite ressaltar e identificar nelas características comuns para grupos específicos. Essas características podem ser eixos temáticos em destaque para ensinar a cidade na escola básica, sobretudo em contexto latino-americano.

Nesse sentido, conhecer melhor a cidade, em especial a cidade latino-americana, é uma meta essencial para o trabalho a ser realizado com a Geografia na escola. A formação do conceito de cidade, constituída por uma rede de significados, é relevante para os jovens escolares, para que possam lutar para o exercício pleno de sua vida social e coletiva.

Com o intuito de demonstrar caminhos para cumprir essa meta, serão apresentados, ao longo deste artigo, um conjunto de cenários que podem servir de recurso didático para 
o tratamento desse tema. Esses cenários estão articulados em três eixos, fundamentados em abordagens teóricas da Geografia Urbana, discriminados da seguinte forma:

1. Desigualdades socio-territoriais

2. Espaço público, mobilidade e acessibilidade

3. Relações cidade-campo

Os três eixos propõem novas visões acerca dos conteúdos que são ensinados nas escolas cotidianamente, porém, nem sempre de forma consistente e crítica, de modo a permitir a formação de um pensamento teórico e abrangente a respeito. Sua abordagem a seguir pretende ser uma possibilidade de trabalhar com a meta da formação de um pensamento teórico pelo olhar da Geografia.

\section{Cenários urbanos como fragmentos da vida cotidiana e o desenvolvimento do pensamento geográfico}

As características próprias das cidades contemporâneas (grandes e pequenas), sobretudo em sociedades economicamente periféricas, podem ser identificadas em situações específicas? Como se pode identificá-las?

A aposta que fundamenta os argumentos do texto é a de que é possível orientar atividades de ensino, tendo como meta problematizar a vida cotidiana dos alunos e apresentar contribuições da Geografia para a compreensão de aspectos desses problemas, que é o conhecimento sistematizado por essa ciência, para que os alunos formem conceitos sólidos e abrangentes sobre cidade, sobre essa espacialidade.

Compreende-se que a leitura dos espaços da cidade pode ser feita pela Geografia, o que contribui significativamente para sua compreensão. Esse campo do conhecimento constitui um conjunto de conceitos, princípios, categorias e teorias que permitem analisar a produção e reprodução do espaço urbano, tanto em sua dinâmica, com os agentes envolvidos. São conceitos mais abrangentes para essa análise, tomando como parâmetro a dinâmica da vida cotidiana, a paisagem, o lugar e o território, dos quais certamente derivarão outros. A paisagem como expressão das formas espaciais que expressam o conteúdo social; o lugar como local que tem seu significado para o sujeito, mas que deve ser visto em sua multiescalaridade; e o território, como espaço apropriado por grupos determinados pelas relações de poder. ${ }^{1}$

Esses conceitos possibilitam, por sua vez, perceber características mais específicas da relação dos diversos sujeitos com a cidade, o que é fundamental para uma aprendizagem significativa na Geografia. A leitura sistemática da paisagem, por exemplo, permite identificar diferenças que são reveladoras das desigualdades sociais expressas nas áreas segregadas; as dificuldades e as condições de mobilidade indicam consequências perversas da fragmentação urbana, o que pode ser explorado com o conceito de lugar.

1 Meu entendimento desses conceitos está exposto sistematicamente em outros trabalhos publicados, como em Cavalcanti, 2012. 
Assim também, a análise de território mostra que a existência de locais com problemas de acessibilidade, evidencia as apropriações de território dominantes nesse espaço.

A observação atenta de cenários urbanos cotidianos, com a contribuição dos conceitos geográficos já referidos ajuda, portanto, na compreensão e reflexão sobre o que eles representam. Esses cenários são fragmentos da vida cotidiana, sua observação e análise é possível pelo pensamento geográfico. Como? A observação da paisagem e o olhar cuidadoso para o que ela expressa, a consideração de suas particularidades e das relações das diferentes pessoas com esse local, como lugar, e a consideração das redes de poder e apropriação pelos grupos que ali estão representados, podem ser caminhos para essa identificação, o que pode ser orientado na escola, propiciando assim a formação do pensamento geográfico.

Tomando como base as considerações anteriores, a seguir são apresentados alguns cenários do cotidiano (são vistos aqui como exemplos atuais de fatos e acontecimentos comuns em distintas cidades) sob o olhar geográfico. O desenvolvimento desse olhar é uma meta no ensino de Geografia e, tendo em vista essa meta, professores de Geografia podem partir de sua própria experiência na cidade, destacando imagens, músicas e textos acadêmicos e literários sobre cidade e vida urbana, que circulam nos meios de comunicação, para serem utilizados em suas aulas. Mas, também eles podem solicitar que os alunos façam isso, trazendo materiais que tratem de sua realidade cotidiana. O importante é que esses materiais sejam usados como problematizadores dos temas urbanos trabalhados na Geografia e que sirvam como eixo de ligação da Geografia acadêmica, científica, com a geografia vivida pelos estudantes.

Para tanto, não há um modelo, um critério ou um roteiro para leitura dos textos e das imagens. O professor pode explorar esse material como considerar conveniente. Particularmente, tenho sugerido como percurso didático para a mediação do professor as etapas de problematizar -sistematizar- sintetizar, a ser seguida em cada unidade temática. No caso desses cenários, entendo que eles podem ser bem adequados ao primeiro momento do ensino de uma unidade o de problematizar o conteúdo, buscando que os estudantes tenham ao longo dos outros momentos uma nova compreensão do mesmo.

Cada cenário, portanto, pode ser analisado geograficamente por um conjunto de conceitos explicativos. A intenção é de apresentar situações da vida urbana cotidiana que podem servir como problematizadores dos conteúdos escolares a serem trabalhados em um percurso didático de sala de aula. Eles podem ser, assim, utilizados em diferentes momentos no ensino com a meta de formação de conceitos que envolvem a espacialidade urbana, como os de paisagem, território, lugar, entre outros.

\section{Cenário Urbano 1}

\section{Final de tarde, avenida central de uma cidade}

A cena acontece em um dia de chuva no final da tarde. Estou em uma avenida central, e sou tomada pelas típicas chuvas convectivas de verão, exatamente aquelas que dão medo pelas enxurradas! Na via, é grande a pressa dos motoristas que passam por mim feito loucos... para chegar em casa. Eu também estou circulando rápido, mas tenho que parar no sinal vermelho. Então, ali parada, 
olho para os lados e vejo um ponto de ônibus, com muita gente, alguns sentados, outros de pé. Muita gente! O mobiliário que abriga os virtuais passageiros não os comporta e tampouco os protege da chuva (poderia ser do sol, do vento, ou daqueles que querem roubá-los!). Todos estão com seus pacotes e bolsas que carregam todos os dias - de casa para o trabalho, ou para escolas, e de volta para casa-, estão cansados de uma jornada longe de suas casas, dos seus afetos. Eu me encontro sozinha no carro, estou abrigada da chuva, ouço rádio enquanto vou me "livrando" dos outros carros e obstáculos do movimento, meio irritada com a lentidão do trânsito... Olho uma outra vez para aquela parada e penso: eles também estão irritados? Certamente, mas... que alternativas eles têm para irem para casa? Após dezenas de minutos esperando ali, provavelmente eles entrarão nos ônibus que os levarão para o destino. Quanto tempo e em que condições ficarão dentro do ônibus? Entre uma e duas horas de pé, em um ônibus lotado, é a mais provável previsão. Fico ali, pensando que, de fato, a rotina nas cidades grandes é estressante e requer, de todos, paciência e habilidade para cumprir as atividades diárias para viver. No entanto, sei que essa rotina não é igual para todos os habitantes, pelo contrário, ela é muito desigual!

(Cavalcanti, 2016 - registro de observação de campo)

A não inclusão de imagens em todos os cenários se justifica pelo fato de que se quer explorar diferentes tipos de linguagens: verbal, imagéticas.

Esse é um cenário muito recorrente e serve para ilustrar o que ocorre no cotidiano das cidades. Ele revela a lógica que predomina nesse espaço. A paisagem é o conceito mais geral que permite sua análise, como uma "porta de entrada" para a apreensão dos processos que resultam naquele conjunto de elementos. Observando a cena, sua localização, suas formas, a disposição espacial e a exposição das pessoas e objetos urbanos (Gomes, 2013), pode-se apreender conteúdos da sociedade ali representada, pode-se concluir sobre quem tem a prioridade nas ruas, nos deslocamentos, na mobilidade.

A inquietação própria dos sujeitos pode levar a questionar essa paisagem observada: quem pode e consegue se locomover na cidade? Por que é possível uma situação tão desigual e ao mesmo tempo tão corriqueira no dia a dia das cidades? Por que pessoas que têm condições materiais muito diferentes convivem com essa realidade e reproduzem pacificamente essa situação? Há alternativas para o deslocamento para os pobres que vivem em áreas distantes do centro da cidade e muitas vezes até destituídas dos serviços básicos e de possibilidades de trabalho e escolas? O sistema de transporte público poderia ser diferente? É possível planejar a cidade para alterar essas condições de deslocamento e acessibilidade para a maioria da população?

Essas são questões que ajudam a iniciar uma discussão, acionada pela observação ou imaginação desse cenário, que leva a desnaturalização da prioridade do transporte individual, da lógica de lucro do transporte coletivo e das condições de acesso a esse transporte. Essa problematização pode ser seguida de informações e reflexões/análises que terminam por conceber o transporte público, entre outros elementos, como um sistema que tem seu funcionamento definido por um modelo de desenvolvimento social e econômico, e que qualquer alteração substancial nele só é possível por alterações estruturais desse modelo. 
Aprofundando um pouco mais na discussão, é adequado destacar uma característica relevante na análise das cidades contemporâneas que é a fragmentação espacial. Segundo Jirón e Mansilla (2014), esse é um dos fenômenos urbanos que se imprimem com mais força sobre essas cidades, conforme expressam os autores:

Con o conceito de fragmentação se hace referencia a la segmentación y la atomización del espacio urbano, las que generan discontinuidades espaciales que limitan la unificación del conjunto urbano. La noción de fragmentación permite, entonces, describir las lógicas de separación, extensión y nuevas fronteras urbanas, que establecen distinciones entre los diversos grupos sociales (2014: 6).

As análises do espaço urbano fundamentadas nesse conceito, destacam o caráter de descontinuidade, segmentação e atomização de áreas que ocorre em determinado modo de produção e expansão do espaço urbano que, por sua vez, materializa e acentua a condição de desigualdade social nesses espaços, gerando, de um lado, áreas valorizadas e, de outro, áreas marginais. Nesse caso, as cidades, com suas paisagens, aparecem como cenários de desigualdades.

Segundo Jiron e Mansilla (op. cit.), para compreender o fenômeno da fragmentação dos espaços das cidades, é preciso avaliar sua temporalidade, entendida como mais do que somente o tempo cronológico; incluindo a relação entre seus fragmentos e as consequências dessa fragmentação para a vida cotidiana. Esse fenômeno, para ser melhor avaliado, deve ser articulado ao de segregação. Ambos contribuem para a compreensão da organização da cidade por grupos distintos e desiguais (separados entre si), resultantes da forma capitalista de produção do espaço contemporâneo. Ao analisar a cidade por esses aspectos, percebe-se a importância de se refletir sobre seus impactos na vida cotidiana, ou seja, sobre a forma como eles interferem nas práticas de todas as pessoas e de grupos sociais diversos. Este último aspecto é justamente o enfoque deste artigo.

A fragmentação faz referência ao processo de produção da cidade em pedaços, isolados, separados, desconectados, escondidos, e por vezes, até protegidos por barreiras (como os muros dos condomínios fechados, as autopistas, grandes áreas vazias entre áreas urbanizadas). Trata-se de um conceito que junto com o de segregação expressam, como já foi dito, a complexidade das práticas sociais, econômicas e culturais que ali acontecem.

\section{Cenário Urbano 2}

\section{Notícia em jornal de Goiânia: Lojistas protestam contra ambulantes}

Os lojistas da Região da Rua 44, no Centro de Goiânia, voltaram a protestar na tarde de ontem contra a presença de ambulantes e a falta de fiscalização da Prefeitura de Goiânia. Eles exigem a retirada dos informais do local, que estariam prejudicando as vendas das lojas e tumultuando o ir e vir da clientela. Até então, segundo a Associação dos Lojistas da 44 (AL44), a Prefeitura ainda não se posicionou sobre o caso, mas novas manifestações já estão agendadas para esta semana, inclusive com visita prevista à Câmara Municipal, no dia 14 de setembro. 

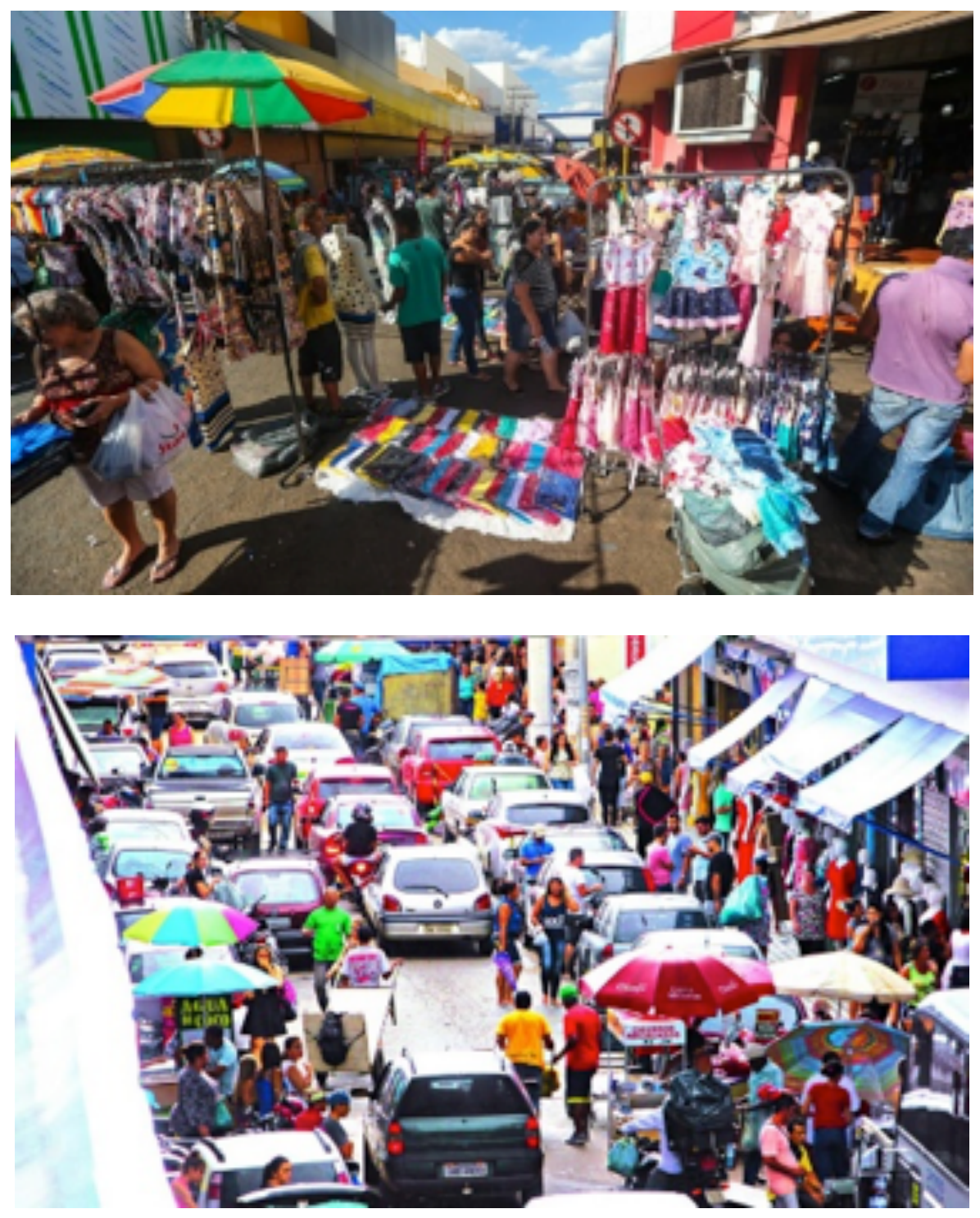

Figuras 1 e 2. Comércio popular na Rua 44 / Goiânia-Brasil. Fonte: Jornal 0 popular (2017)

Nesse cenário, ao ler a notícia e observar as fotografias pode-se perguntar: de quem é o espaço? A Rua é pública, os ambulantes (chamados na reportagem de informais) podem, por essa razão, ocupá-la para exercerem sua atividade? Os donos das lojas (lojistas) que se localizam nessa rua têm direito a solicitar a retirada dos ambulantes nas calçadas e ruas que ficam em frente a suas lojas? Como resolver essa questão? É questão de planejamento? É uma questão policial? É uma questão de justiça espacial?

De um lado, os lojistas reclamam, de acordo com a reportagem, da concorrência desleal dos ambulantes, e dizem que sua presença no local e nas imediações faz com que suas vendas reduzam consideravelmente. E, além do mais, é motivo de reclamação da sociedade o fato de que a presença de armações, tipo "barraquinhas", dos ambulantes toma conta das ruas, muitas vezes chegando a impedir a passagem dos veículos e dos pedestres. De outro, os ambulantes, ainda de acordo com a reportagem, afirmam que 
querem apenas vender seus produtos e com isso garantir sua sobrevivência e de sua família. Em muitos casos, a opção pela atividade do comércio informal está ligada à condição de emprego ou à falta dele. Os conflitos que surgem dessa situação não são poucos e menos ainda são de fácil solução.

Trata-se de um cenário também bastante comum nas grandes cidades de vários lugares do mundo, mas certamente em cidades de mundos periféricos, em países pobres, essa cena é mais frequente e, provavelmente, os conflitos são mais amplos. Ela é uma cena do cotidiano banal, que serve para analisar a cidade enquanto território e espaço público. Espaço público do ponto de vista de quem? Espaço público é território de quem? Como podem ser e como são definidos esses territórios?

Os territórios, pela reflexão geográfica, são espaços resultantes de apropriações de grupos (Estado, segmentos sociais, pessoas), porém, as análises advertem que essas apropriações são dinâmicas e podem ser momentâneas ou permanentes, regulares ou não, estáveis ou instáveis, flexíveis ou não. Cabe então, compreender como se estabelecem, ou se estabeleceram, as correlações entre os diferentes grupos e interesses naquele local, para resultar na coexistência entre lojas formalmente constituídas e vendedores de rua, por exemplo. Essa mesma compreensão identificaria as razões dos limites dessa coexistência, face aos conflitos de interesse latentes, que parecem estar evidenciados nesse cenário. Nele, a rua aparece como espaço público, como espaço do conflito de diferentes grupos. A solução por seu uso mais adequado depende de uma franca e democrática negociação, buscando contemplar, de modo justo, o interesse da maior parte da população.

Outro conceito também salientado por especialistas dos estudos urbanos na América Latina, é o de gentrificação, que significa o processo que culmina em grandes reconfigurações de espaços centrais da cidade e seus adjacentes, com finalidades de valorização dessas áreas. Esse processo implica em retirada de moradores dessas áreas até então degradadas (ou a retirada dos vendedores informais de rua, com a finalidade de modernizar o espaço para valorizar seu uso), via de regra composta por grupos de baixa renda, para dar lugar a espaços residenciais, comerciais e de serviços, produzidos para usufruto de pessoas com maior poder aquisitivo. Conforme Janoschka (2016), esse processo envolve a remoção involuntária da população residente, por mecanismo de desapropriação, e sua reacomodação em áreas periféricas da cidade. Conforme o autor, a intervenção urbana desse tipo consiste:

(...) en expulsarles [os moradores antigos] de los lugares céntricos de la ciudad, en los cuales están demasiados visibles para que "funcionen" las estrategias de revalorización. Para mayor claridad, cabe señalar que la limpieza social y la "modernización selectiva" de las ciudades latinoamericanas se fundamentan en mecanismos de acumulación por desposesión del hábitat.

\section{E acrescenta:}

(...) la acumulación por desposesión del hábitat como lente analítica permite comprender los principios de reestructuración de las ciudades latinoamericanas desde una perspectiva holística. En este sentido, el desplazamiento es un mecanismo central de la desposesión que implica la rearticulación urbana reciente, y se manifiesta en cuatro dimensiones: la material, política, simbólica y psicológica (2016: 64). 
LANA DE SOUZA CAVALCANTI

Em razão/decorrência da fragmentação, gentrificação e segregação espaço-temporal nas cidades, os sujeitos têm suas práticas cotidianas também fragmentadas e restringidas, e são impelidos a encontrar estratégias para sobreviverem nos interstícios da cidade (trabalhando na rua e de modo informal, se for necessário), para fazerem deslocamentos em grandes distâncias, por esses fragmentos, com o objetivo de ampliar assim suas possibilidades de vida social. Esse fato leva a incorporar outro aspecto apontado como relevante na análise da dinâmica urbana atual: a mobilidade.

A mobilidade não se refere somente aos deslocamentos físicos em si, mais também está relacionada à consequência e significado desses deslocamentos. Esse conceito é muito pertinente na análise do espaço intra-urbano, pois permite descrever e interpretar as práticas cotidianas dos habitantes.

\section{Cenário Urbano 3}
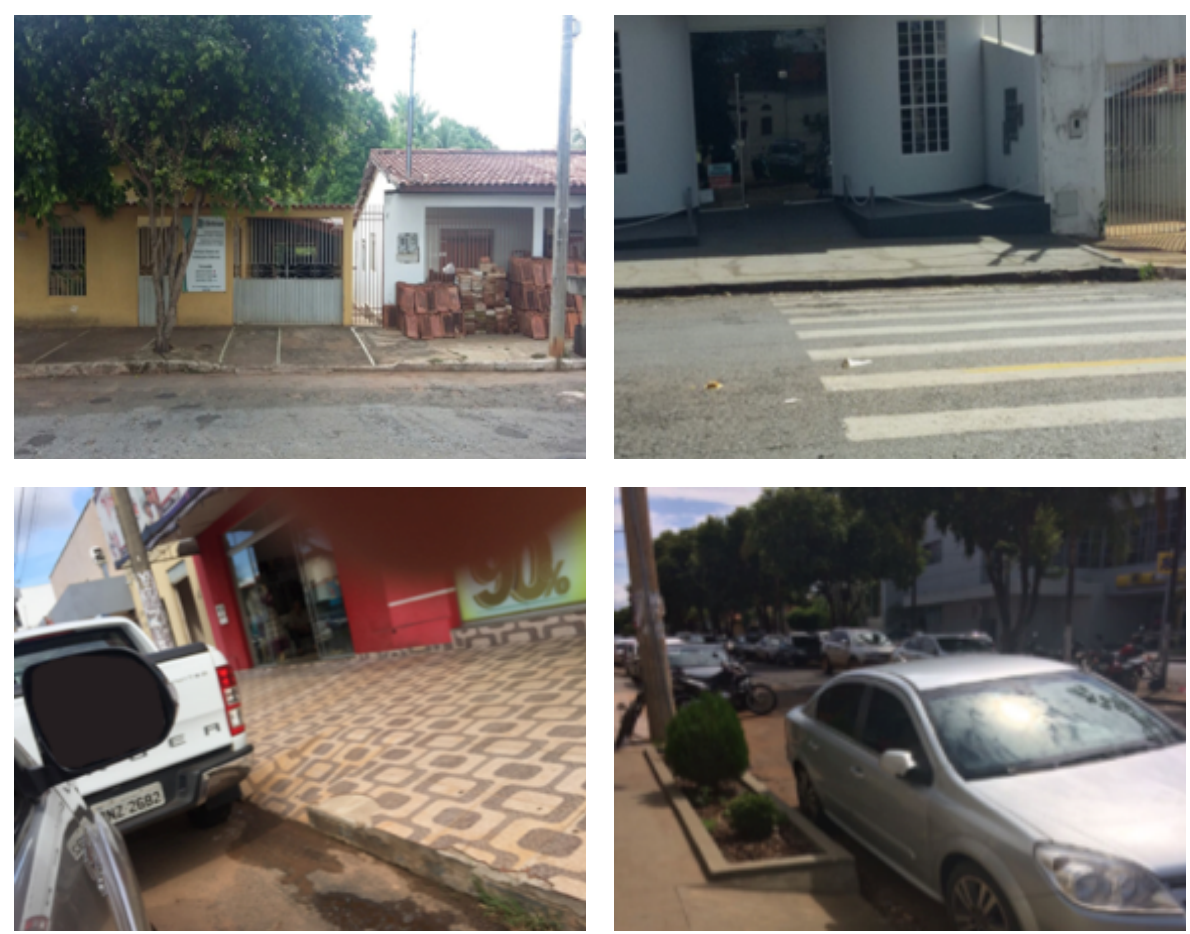

Figuras 3, 4, 5 e 6.0 espaço público: a acessibilidade e a mobilidade urbanas e sua relevância na formação de jovens cidadãos. Fonte: Alunos do E.M do Colégio Exato (2016), organizado por Almeida (2017).

As observações nas paisagens urbanas e o registro destas por meio de imagens, como as que foram destacadas nesse cenário, feito por estudantes do nível médio em uma atividade de ensino, podem revelar várias características desse espaço. A questão da mobilidade, por exemplo, como a abordada no Cenário 1, pode ser associada ao tema da acessibilidade urbana -tópico de estudo realizado por Almeida (2017) - quando se observa as condições dadas ao deslocamento de pedestres. Nas fotos deste Cenário 3, estão evidenciadas marcas das relações que se estabelecem entre os gestores da cidade e seus habitantes e entre os próprios habitantes: as condições de passagem pelas ruas, de acessibilidade das calçadas; as condições de deslocamento e acessibilidade dada pelos gestores, e respeitadas pelos habitantes (aqui se destacando os proprietários de carros) às pessoas com deficiências. 
É possível, pela observação dessas cenas/imagens, compreender o significado das normativas urbanas, no sentido da democracia e da justiça espacial. Por um lado, já se pode perceber um avanço do ponto de vista da gestão urbana quanto à produção de espaços acessíveis, estampada na definição de faixas de travessia de pedestre, de rebaixamento de calçadas em locais específicos. Por outro, percebe-se que grupos de habitantes ainda não reconhecem os direitos coletivos -duramente conquistados por grupos sociais específicos ao longo da história, como por aqueles que têm algum tipo de deficiência física- e não pautam suas práticas considerando o coletivo, a necessidade do outro, mas levando em conta os interesses individuais. Por essa razão, quando circulam com seus carros pela cidade, não respeitam, por exemplo, as rampas de rebaixamentos de calçadas para travessia desses sujeitos e estacionam seus carros obstruindo justamente a rampa de acesso (conforme pode ser visto nas fotos).

Percebe-se assim que a discussão que pode ser gerada pelo estudo dessas fotografias com jovens escolares, por exemplo, em aulas de Geografia, é relevante para compreender o significado dos espaços da cidade, sua dinâmica, o uso público que deve ser dado a eles, a relação que têm com a vida coletiva e cidadã.

Assim, a análise da mobilidade e acessibilidade urbanas é bastante fecunda para compreender a relação entre espacialidade e vida cotidiana. Nesse enfoque, articulando-se a essa rede de conceitos, aparece o tema dos espaços públicos. Por que esse também é um conceito a ser explorado quando se quer pensar na relação cidade, cidadania, vida urbana em busca da justiça espacial (Soja, 2014)? Os espaços públicos são, por excelência, os locais da cidade de acesso para o usufruto das pessoas em geral, conforme buscar-se-á demonstrar adiante.

A compreensão é de que há uma relação estreita entre espaço público e cidadania sendo que, nesse tipo de espaço, como as ruas, as praças e os parques, estão previstas as práticas coletivas e individuais que ocorrem na copresença e pela exposição; características próprias do movimento social. Nesses espaços são latentes as situações de compartilhamento, de conflito e de divergência, e as possibilidades de manifestação, de contestação e de resistência. Eles são lugares do encontro de pessoas e práticas estranhas entre si, lugares do imprevisto e do imprevisível; lugares da luta, do conflito, da (in) visibilidade. Enfim, são públicos quando as pessoas dão uso e significado público a esses espaços.

Os espaços públicos, assim entendidos, cumprem papel importante na democratização das cidades e na prática da cidadania, pois, como está sendo formulado, eles são apropriados pelas pessoas para diferentes finalidades da vida pública, marcada pela socialização, copresença, visibilidade, exposição, improvisação e imprevisibilidade. Nesse sentido, eles são também fundamentais como fator de definição da vida cotidiana nas cidades para diferentes grupos sociais.

Nessa perspectiva é que se aborda aqui o conceito de acessibilidade associado ao de mobilidade. Para a análise desses conceitos e de sua relação constata-se, de início, que, com o nível de desenvolvimento tecnológico atual, é comum afirmar-se que a vida cotidiana é marcada pela velocidade, mobilidade e fluidez nos espaços. Mas, cabe perguntar: essa mobilidade é para todos? Ela é igual para todos os habitantes das diferentes cidades? Como os habitantes ficam afetados em sua mobilidade nas 
cidades segregadas e fragmentadas? Algumas análises já avançam em respostas para essas questões: em sociedades que apresentam as características antes abordadas, as pessoas têm suas mobilidades condicionadas às suas condições materiais, que definem seu lugar de moradia e de trabalho, e levam à imobilidade uma parcela significativa dessa população.

Outras questões também são relevantes: quais são as práticas do planejamento que contribuem para esse modelo de espaço urbano e reforçam esse estado de mobilidade muito restrita de boa parte das populações citadinas? Essas práticas poderiam ser representadas pela especulação imobiliária, pelo deslocamento prioritário por automóvel, pela rede de transporte público deficiente, pela malha viária concêntrica? Certamente todos esses fatores têm seu papel na definição dessa realidade, cujas diferentes combinações geram espacialidades urbanas específicas. Essa série de fatores no contexto de grande parte das cidades latino-americanas, aliada às precárias condições de atendimento às demandas prioritárias dos moradores dos bairros -sobretudo os periféricos- que forçam as pessoas a se deslocarem para os locais mais centrais e mais bem servidos, potencializam as condições também precárias dos deslocamentos urbanos diários.

Blanco et al. (2014) denominam motility o capital espacial dos citadinos, que é a capacidade que eles têm de ser móveis (envolvendo três aspectos: acesso, competência e apropriação). Segundo os autores, na Região Metropolitana de Buenos Aires, conforme investigação, a mobilidade está relacionada em grande parte ao poder aquisitivo das pessoas, ou seja, aqueles que têm maior renda têm maior mobilidade na região, ao contrário daquelas cujas rendas são pequenas. Sua linha de investigação demonstra a relevância do fator mobilidade na qualidade de vida urbana cotidiana, concebendo-a como uma necessidade e um direito, pois ela define as possibilidades de acesso aos serviços básicos para o desenvolvimento da vida social, a participação nas atividades e para a socialização.

Buscando salientar a relevância do lugar para a experiência e vivência das pessoas, na medida em que lhes dá significado, Da Silva Brum (2017) faz referência a um novo paradigma da mobilidade, e a novas formas de deslocamento, de fluxos, de um alargamento das redes e conexões, o que leva a repensar o papel da mobilidade na estruturação e na experiência do mundo contemporâneo. Chama a atenção também, para o contraponto dessa realidade, aproximando-se da abordagem que está sendo dada nesse texto à problemática em questão: a desconexão e a fragmentação territorial. Essa situação paradoxal está relacionada, por sua vez, à distribuição desigual no espaço das possibilidades mais avançadas de deslocamento, produzindo geografias de exclusão, de desconexão, de desigualdade e de imobilidade. Compreendendo a mobilidade como um movimento físico, como uma experiência pessoal e uma prática social que tem significado simbólico, essa linha de raciocínio reforça a ideia de que ela tem um papel fundamental na configuração do cotidiano das pessoas e em suas possibilidades de usufruto da cidade. O autor dá destaque para a conclusão de que cada indivíduo cria seu próprio mundo dentro de suas estratégias de mobilidade: "a experiência que uma pessoa tem sobre seu bairro ou cidade está, em certa medida, comprometida com os trajetos percorridos, a forma como o movimento é realizado e os locais que engendram esses movimentos" (Da Silva Brum, 2017: 113). 


\title{
Cenário Urbano 4
}

\section{São Paulo: Projeto de Lei que criminaliza o Funk tramita no congresso brasileiro}

\begin{abstract}
"A história não é nova. Já aconteceu com o Maxixe e até com o Samba no início do século 20... A proposta [de criminalização] foi enviada em janeiro por Marcelo Alonso, um web-designer de 47 anos, morador de um bairro da zona norte de São Paulo. A ideia teve mais de 21 mil assinaturas em menos de quatro meses e agora precisa ser analisada pelo Senado Federal. Para Marcelo, o funk tem ligação direta com o aumento da criminalidade dentro das comunidades. [...] 'A falta de política pública empurrou o funk somente pra dentro da favela. E dentro da favela se criou a opinião, depois da morte do Tim Lopes [jornalista que em 2002 foi morto, por traficantes, enquanto realizava uma reportagem sobre abuso sexual de menores e tráfico de drogas em um baile funk na favela Vila Cruzeiro, Rio de Janeiro], que baile funk é reunião de traficantes', avalia Leonardo. [...]. Os versos pesados, normalmente, estão na batida dos 'proibidões', como são chamados os funks mais explícitos [...] Os proibidões são a maior atração nos fluxos, como são chamadas as aglomerações de jovens para ouvir funk nas ruas das periferias".
\end{abstract}

\section{[...] CBN, Cultura, 04/09/2017.}

A descrição dessa polêmica diz respeito a aspectos das práticas espaciais de jovens. Atividades de lazer que ocorrem em muitas cidades latino-americanas, como as festas de rua, são práticas espaciais de jovens que se apropriam de locais públicos tornando-os seus territórios, para execução de estilos musicais escolhidos e para seu usufruto. Por um lado, parece legítimo que os jovens possam se divertir, usufruir dos espaços para realizar suas práticas, principalmente quando se considera que para eles -os jovens de periferia pobre da cidade- lugares fechados destinados a festas não são muito acessíveis, pois depende de aporte financeiro. Por outro, para os moradores da região onde acontecem as festas, para os que querem transitar simplesmente pela rua, esse tipo de prática naquele local pode ser visto como inapropriado. Quem tem razão? Quem tem o direito de usufruir daquele espaço? Como e quem pode decidir sobre essas questões?

Novamente, trata-se de cenas banais no cotidiano da cidade, que tem relação com os conceitos de espaço público e de território. As cenas falam desses conceitos e colocam em questão sua natureza, sua dinâmica, sua legitimidade. São temas polêmicos que podem estar presentes nas aulas de Geografia, gerando interesse e debate entre os jovens escolares sobre suas práticas, seus direitos, sua responsabilidade social e sua cidadania. Não são temas para serem tratados de modo simplificado, pois eles não são, de fato, de simples equacionamento, mas é importante levantar o debate que tem a potencialidade formativa relacionada à possibilidade de combater uma visão totalizante a respeito dos habitantes da cidade.

Essa visão produz noções de práticas sócioespaciais desejáveis, generalizadoras e padronizadas, tomando como referências os grupos dominantes. Essa potencialidade está justamente na possibilidade de introduzir teorias sobre a cidade que deem conta de sua diversidade, da variedade de experiências que nela ocorrem e das 
LANA DE SOUZA CAVALCANTI

probabilidades de construção de diferentes significados a esse respeito pelas pessoas e grupos que frequentam seus espaços. Esses são elementos básicos para a prática de planejamento e da gestão urbana democrática e inclusiva, e é importante que sejam compreendidos pelos cidadãos, como os jovens escolares.

Foram salientadas até aqui algumas características do espaço urbano que tem particular potencialidade na análise da vida urbana cotidiana dos diferentes grupos que vivem na cidade, com vistas a orientar a estruturação de conteúdos escolares, tendo como meta o ensino de cidade. Um desses grupos sociais, que tem uma forte relação com a cidade, é o segmento de jovens, considerado em sua diversidade. ${ }^{2}$ Os jovens têm com as ruas, praças e parques, uma forte relação; nesses espaços eles exercem suas práticas rotineiras e delineiam suas identidades. A cidade torna-se para eles, nessas práticas, um cenário pleno de símbolos e sentidos em contínua reconstrução, um espaço que pode ser explorado, reproduzido, apropriado, em seu cotidiano. Os jovens, em especial aqueles com quem lidamos nas escolas de nível básico, os jovens escolares, ${ }^{3}$ se desenvolvem e se constituem cotidianamente nesses espaços, com o repetido e previsível, e com a possibilidade de contestação e realização de novas práticas, não previstas nem esperadas, tornando assim a cidade mais viva e em movimento.

\section{Cenário Urbano 5}

Espaço público em áreas segregadas

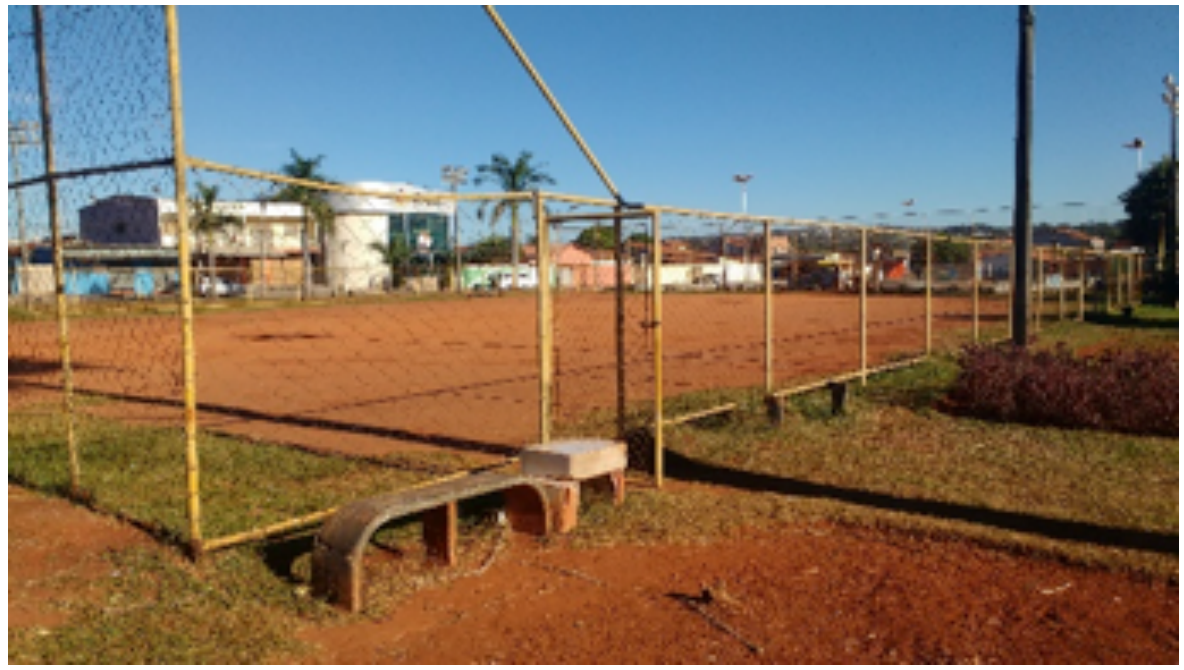

20 jovem escolar aqui é considerado como uma das expressões da categoria social juventudes. Tenho expressado minha compreensão sobre essa categoria em diversos trabalhos publicados $(2016,2015,2011)$ por entender que seu entendimento com profundidade contribui sobremaneira para as reflexões e tomadas de decisão sobre o ensino básico, particularmente o de Geografia, pois, juntamente com as crianças, os jovens são os sujeitos desse processo.

3 Embora nesse texto esteja me referindo ao trabalho com a Geografia na escola básica, que inclui estudantes até os 17 anos (desde a etapa da educação infantil até o nível médio), meus estudos têm priorizado os últimos anos do ensino fundamental e o ensino médio que, em geral, corresponde ao ensino de Geografia para etapas em que predominam estudantes de 13 e 14 aos 17 anos. 

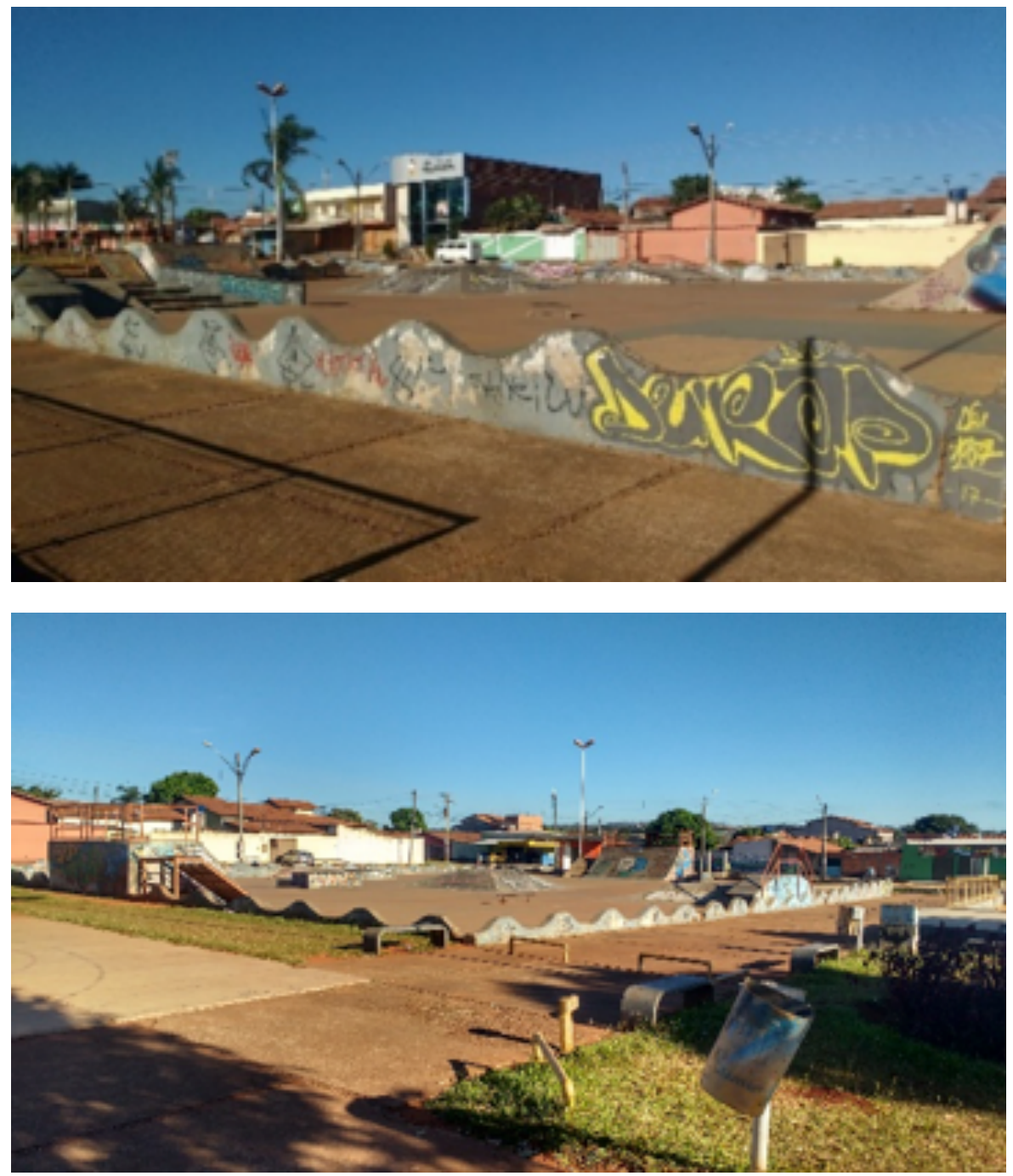

Figuras 7, 8 e 9. Os espaços públicos de lazer. Fonte: Araujo, 2017.

Esse cenário é um conjunto de fotografias de um espaço de lazer chamado Praça da Paz, de um bairro periférico, segregado, de Goiânia. Alguns elementos de sua paisagem são importantes para pensar a cidade e sua dinâmica. Por que essa praça tem esse arranjo espacial? Provavelmente seu projeto e sua construção, levando em consideração o local em que está, buscaram os baixos custos. Isso explicaria a singeleza de suas formas? A falta de vegetação? A falta de manutenção? Mas, outro aspecto chama também a atenção: seu esvaziamento. Com essas características, a praça não atrai as pessoas para frequentá-la? Por que as pessoas não usufruem desse espaço público?

Essa é uma praça localizada próxima a uma escola, onde foi realizada uma pesquisa com alunos jovens de ensino médio. Esses jovens, em debate com o professor de Geografia, apontaram a pouca frequência a esse espaço em razão de não oferecer segurança e não ter manutenção, revelando-se para eles locais perigosos e sujos. Segundo o autor dessa pesquisa: 
(...) um elemento principal da segregação vivenciada pelos jovens alunos estava na questão que residia sobre a falta de equipamentos urbanos para o lazer. Muitas vezes, as atividades se limitam a casa dos alunos. Entende-se que os espaços públicos oferecidos nos bairros poderiam ser espaços importantes para que essa vivência fosse permitida. Entretanto, esses espaços não foram bem avaliados pelos alunos, sendo a falta de segurança, a violência e a limpeza aspectos que impedem seu uso (Araujo, 2017: 101).

Trata-se de um tema já destacado como importante para a sala de aula, os espaços públicos e seu uso, quando se tem como meta a formação de conceitos referentes à cidade pela Geografia, para orientar a vida cotidiana cidadã. O tema pode abordar questões do planejamento, da produção social da cidade e do direito ao seu usufruto. Como já foi mencionado, os espaços públicos são os lugares da cidade que se destinam basicamente à vida coletiva, e onde ocorre o movimento social, com suas possibilidades de conflito e divergência, de contestação e de resistência, sendo assim muito relevante para práticas cidadãs e para a vida social.

Nesse caso, o eixo referente às desigualdades socio-territoriais tem destaque nessa análise. A cidade é um espaço que se produz e se reproduz para viabilizar coletivamente as atividades/necessidades cotidianas das pessoas que abriga: morar, dormir, se abrigar, trabalhar e estudar, comprar. Essas atividades são contextualizadas, dependendo de uma série de fatores, entre os quais destacam-se os econômicos e culturais. Para a produção da vida, assim, as cidades se organizam em zonas de alta densidade de serviços, de aglomeração de pessoas e de edifícios, e em zonas residenciais. Porém, a expansão das cidades e a lógica de sua produção têm a contribuição de distintos agentes como os proprietários dos meios de produção, os proprietários fundiários, os promotores imobiliários, o Estado e os grupos sociais excluídos (Correa, 2011). O resultado é a distribuição espacial mais complexa que agrega outras particularidades.

Com efeito, alguns outros atributos dessas referidas cidades, sobretudo no contexto latino-americano, são frequentemente apontados por especialistas, entre eles os geógrafos. Um fenômeno a ser destacado aqui, para qualificar esses espaços, é o da segregação sócioespacial. Esse fenômeno refere-se ao processo de produção de zonas complementares na cidade, que são produzidas para destinar a vida de grupos determinados em áreas específicas da cidade. Trata-se de um conceito em discussão quanto ao seu significado para qualificar processos amplos de separação de áreas urbanas, não necessariamente explícitos. $\mathrm{O}$ entendimento de segregação residencial formulado por Correa (2013) é interessante para compreender esse processo, pois para ele tal fenômeno significa a concentração de diferentes classes sociais no espaço urbano, que são homogêneas entre si e heterogêneas em espaços diferentes. Importa entender aqui, sobretudo, a vinculação desse processo para a vida urbana cotidiana. Segundo Carlos (1996), esse processo tende a separar e a dividir hierarquicamente os habitantes na cidade em função das formas de apropriação do solo.

Com essas características, associada à situação de desigualdade social, ao processo de valorização de áreas urbanas e à destinação de outras áreas para os grupos de habitantes com menor renda, percebe-se que se trata de um processo que interfere diretamente nas possibilidades de usufruto da cidade e de seus espaços públicos centrais, tendo ressonância significativa na vida urbana dos grupos. Em muitos casos, é necessário 
avaliar, de modo associado, o fenômeno da migração para compreender como ocorre a segregação socioespacial, como é o caso de diversas cidades brasileiras. Na análise de Paula (2013), por exemplo, a migração e a segregação foram identificados como fenômenos articulados, pois, a maioria dos migrantes que chegam à cidade têm acesso predominantemente a áreas distantes e segregadas do centro, tendo sua inserção social marcada por essas áreas, o que reforça sua condição de segregação.

Por sua parte, o tema do espaço público para jovens escolares, como já foi abordado, é particularmente importante a ser considerado. Segundo destaca Paula, "fica evidente o papel das redes de sociabilidade das juventudes em sua circulação pela cidade, na apropriação de seus espaços, ou ainda na representação que eles possuem dessa cidade ou nas espacialidades resultantes delas" (2013: 31). Na praça e outros lugares públicos -mas não somente neles- se dão de modo potencial as relações entre eles, a troca de experiência com seus pares, com distintos graus de aproximação e de identificação, e o constante processo de formação de territórios.

\section{Cenário Urbano 6:}

Em Goiás, como em muitos outros Estados brasileiros, houve recentemente um intenso processo de urbanização, seja motivado por taxas positivas de crescimento vegetativo da população, seja por intensos movimentos populacionais do meio rural para o meio urbano, em razão do processo de modernização da produção no campo. Desse processo resultam estreitas relações sociais, culturais e econômicas entre campo e cidade no território goiano, que podem ser visualizadas nas paisagens como formas de presença do rural no urbano e do urbano no rural, como os exemplos a seguir:

Quadro 1. A relação cidade/campo no território goiano. Fonte: Adaptado de Rosângela Spironello (Org.), 2017.

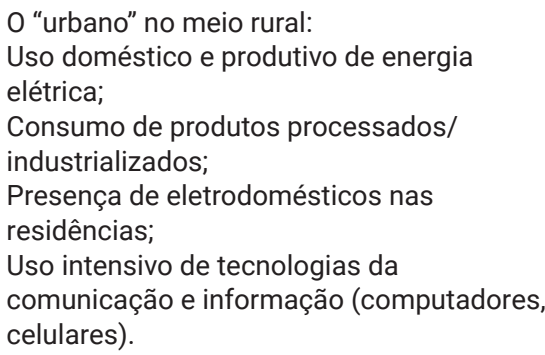

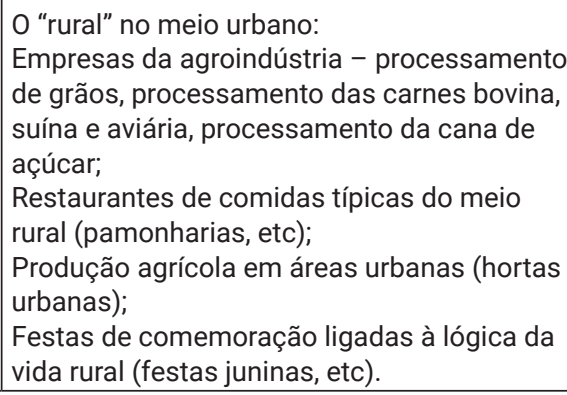

Esse cenário, específico de um Estado brasileiro, é comum em outras regiões da América Latina, fazendo destacar uma característica importante de muitas cidades contemporâneas, que é sua estreita relação com o campo. Essa relação é analisada em diferentes perspectivas, ora tomando as duas espacialidades de modo dicotômico, como realidades distintas, opostas e separadas; ora entendendo-as como dialeticamente relacionadas. Essa última forma de análise busca compreender as duas espacialidades como parte de uma totalidade complexa e inseparável, permitindo identificar o processo e as contradições que lhes são inerentes. De fato, na formação das cidades latino-americanas pode-se observar uma estreita ligação com o desenvolvimento do espaço agrário, sendo 
que a estrutura social ali presente produz espacialidades diferentes e ligadas por redes (de transporte, energia, telecomunicações), resultando em relações complementares intensas, tanto no que se refere às atividades econômicas, quanto à vida social e às expressões culturais. Nessa linha de compreensão, estudiosos alertam: não é adequado adotar posturas ora dicotômicas ora homogeneizadoras, a primeira separa os espaços urbano e rural; a segunda os homogeneíza, com a hegemonia do urbano. Por uma abordagem mais processual, compreende-se diferentemente, que cidade e campo se aproximam pelas possibilidades técnicas e por necessidade da produção social, resultando na modernização da agricultura, no desenvolvimento do capitalismo no campo, nas inclusões de elementos da vida rural nas cidades, ou vice-versa; mas seguem como realidades distintas, contraditoriamente interdependentes, com o domínio hegemônico da vida urbana e com a reafirmação de novas ruralidades (Hespanhol, 2013).

Ainda que compreendendo as estreitas relações que as diferentes cidades mantêm hoje com os espaços do campo, pode-se dizer que elas têm sua especificidade e revelam um modo de vida daqueles que nelas vivem, modo que extrapola as áreas urbanas estritamente e que tende a ser dominante na sociedade (Lefebvre, 2001). Portanto, pode-se compreender a cidade com as mútuas influências econômicas, culturais e ambientais que tem na sua relação com o campo, enquanto uma espacialidade distinta.

Em síntese, os cenários aqui apresentados são alguns daqueles possíveis de serem captados na vida cotidiana nas cidades. O objetivo de colocá-los em evidência no texto está ligado ao propósito de demonstrar como podem ser abordados pelo ensino de Geografia, com o objetivo de desenvolvimento dos alunos, de formação de seu pensamento teórico-conceitual sobre a cidade e sua dinâmica. Eles podem ser tomados como conteúdos geográficos diretamente ligados à vida cotidiana dos alunos, como será destacado no próximo item.

\section{Fragmentos da vida urbana cotidiana como conteúdos geográficos escolares relevantes para jovens escolares}

Os cenários urbanos são, pois, tópicos da realidade cotidiana que, se bem trabalhados em sala de aula, contribuem para o diálogo entre vida dos alunos e conteúdos geográficos. O pressuposto é o de que esse diálogo permite retirar os conteúdos escolares das cápsulas disciplinares, para inseri-lo na vida das pessoas, na vida dos jovens escolares. E nesse sentido, para tornar mais real e possível o diálogo entre os sujeitos do processo de ensino, é relevante também conhecer esses jovens e os aspectos de sua vida cotidiana na cidade.

Algumas investigações ${ }^{4}$ trazem como resultados elementos da realidade vivida por jovens escolares, que vivem e frequentam escolas em áreas periféricas e segregadas da cidade. Esses jovens revelam uma experiência urbana muito restrita, vivida em pedaços da cidade, via de regra nos pedaços mais próximos de sua residência e/ ou de sua escola. Eventualmente, esses preferem como espaços de lazer as áreas de consumo como os

4 Refiro-me a investigações que tenho realizado ou orientadas por mim (Bento, 2011; Paula, 2013; Pires, 2013; Portela, 2017, Silva, 2016; Araújo, 2017; Almeida, 2017, entre outros). São investigações que, embora trabalhem diferentes temas e enfoques, têm um eixo norteador comum, que é o da relação cidade, cidadania, juventude e vida cotidiana pelo ensino de Geografia. 
shoppings e os parques de diversão, localizados em áreas distantes, mais centrais da cidade. No entanto, eles, na maior parte das vezes, têm sua rotina estabelecida nas proximidades de onde vivem, revelando uma limitação de sua vivência e do conhecimento que têm da cidade como um todo.

A manutenção desse processo reforça a exclusão da possibilidade de uma vida efetivamente urbana e de uma cidade mais justa para o jovem da periferia. Por isso, coloca-se como uma questão central, por exemplo, a importância da formação do conceito de segregação sócio-espacial como eixo articulador entre a Geografia escolar e a formação cidadã. Em sua pesquisa, que trata especificamente desse tema, Araújo (op. cit.) investiga sobre os sujeitos alunos de ensino médio, residentes em áreas segregadas. Seus resultados indicam que os jovens de áreas periféricas têm limitação financeira e por isso trabalham para complementar a renda, eles avaliam o bairro em que vivem indicando alguns serviços públicos como eficientes (disposição do comércio, proximidade de escolas e hospitais, e a disponibilidade de ônibus), mas demonstram insatisfação com os serviços de coleta de lixo e com as condições das praças do bairro. Segundo o autor, a insatisfação com os espaços e serviços públicos foi identificada quando os jovens apontaram as atividades realizadas em seu tempo livre: "na maioria das vezes, os jovens pesquisados realizam atividades que são desenvolvidas dentro da casa, como navegar na internet e assistir televisão" (op. cit.: 120). Sua conclusão é de que os jovens usufruem muito pouco dos territórios juvenis da cidade e que por esses fatores (renda e mobilidade, entre outros) ficam limitados ao espaço do bairro no qual residem, revelando um limite na mobilidade e no seu conhecimento em relação à cidade. E, após um trabalho com esse tema da segregação com os alunos, um depoimento de uma das alunas ilustra bem como eles podem compreender, com a ajuda da atividade escolar, esse processo: "É muito louco. A gente vai sendo jogado para cá porque não tem dinheiro, e eles vão se fechando lá porque tem muito” (op. cit.: 115)

Esses dados reforçam resultados de outras investigações sobre temas correlatos, demonstrando a potencialidade das discussões que abordam a vida cotidiana dos jovens e seus dilemas e desafios. Por essas investigações, conclui-se que os jovens nas grandes cidades brasileiras, que frequentam as escolas públicas, circulam pela cidade frequentemente de ônibus e/ou a pé, portanto com mobilidade e conhecimentos da cidade restritos, destacando-se, muitas vezes, o bairro onde moram e partes do centro original (seus deslocamentos, fora do seu bairro, são ocasionais e extraordinários). Esse dado leva a afirmar que dificilmente os jovens têm, por sua experiência direta e cotidiana, uma visão integrada da cidade e de sua dinâmica. Seu lazer é prioritariamente realizado em casa (o que é reforçado pelo avanço na produção de artefatos tecnológicos e seu acesso) ou nas adjacências da casa, nas ruas, em calçadas, praças, na escola, nas igrejas e em outras áreas públicas, como os parques, shoppings e os bares, boates e casas de show. Neste particular, é interessante notar que em diferentes depoimentos são valorizadas as relações (diretas ou virtuais) com os amigos e familiares. A respeito do trabalho, suas preocupações estão ligadas ao futuro, com a inserção mais efetiva no mercado; mas, mesmo no presente, já buscam empregos para obter renda pessoal (ainda que baixa), para viabilizar gastos consigo mesmo ou eventualmente para ajudar a família. As atividades mais formais, nesse campo, ainda não estão muito presentes no cotidiano da maioria deles; frequentemente trabalham por meio de contrato precário, sem carteira assinada, sem vínculo registrado e com baixa remuneração (Cavalcanti, 2016). 
A consciência de que os jovens escolares de áreas da periferia social da cidade, que geralmente frequentam escolas públicas, têm reduzida experiência cotidiana com a cidade, em função de suas condições materiais de vida e das possibilidades que a própria cidade oferece, leva a potencializar a relevância de um conhecimento mais sistematizado sobre essa espacialidade, contemplando esses componentes de conteúdo aqui abordados, partindo-se de cenas cotidianas que eles próprios vivenciam (ou de cenários mais gerais como os salientados no texto). Está se referindo aqui às possibilidades de análise pela Geografia, e áreas afins, sistemática e abrangente, por meio de abstrações e generalizações viabilizadas por suas categorias analíticas, como as que foram exploradas no texto e acionadas pelas problematizações que surgem do debate sobre os cenários, no sentido de formar conceitos amplos que permitem o desenvolvimento do pensamento geográfico sobre a cidade. Essa é uma meta importante para o ensino de Geografia na escola básica. O tema do pensamento conceitual tem sido a linha de investigação e reflexão que fundamenta a aposta metodológica para o ensino de Geografia que tenho defendido. Nessa linha, os conceitos geográficos são tomados como base do trabalho de mediação didática do professor: eles promovem a capacidade dos alunos de compreender a espacialidade da realidade contemporânea.

O desenvolvimento de um pensamento geográfico, advindo da experiência cotidiana em habitar a cidade, é possível devido à quantidade de processos envolvidos na produção desses lugares. Compreender a cidade por meio do ensino de Geografia pode ser, dessa forma, um elemento central para que as escolas possam formar cidadãos mais críticos e conscientes de que a cidadania é efetivada pela criação dinâmica de direitos e pela consciência da responsabilidade social na luta pela vida democrática e pela justiça espacial. As imagens para serem vistas e imaginadas compõem os cenários urbanos, como os evidenciados no texto. O estudo geográfico pelas imagens que registram e representam o cotidiano urbano pode ser uma ferramenta metodológica importante para a meta da formação do conceito.

A proposta do trabalho docente, com as imagens como cenários urbanos, tem como ponto de partida a convicção de que se a sociedade contemporânea é marcadamente imagética e estetizada. Essa é uma forma de comunicação relevante, para a qual é possível e necessária uma aprendizagem. Tal aprendizagem está na lógica da relevância de se fazer uma experiência crítica com as paisagens, com as imagens (artefatos materiais ou imaginadas). A orientação pedagógica dessa experiência possibilita a organização das experiências do cotidiano, com a mediação do professor. Nesse sentido, concorda-se com Pinheiro (2005), quando se refere à necessidade do olhar crítico para as imagens culturais, o que pode ser adquirido através de diferentes mediações educacionais. Essa autora está se referindo às imagens culturais, nas quais podem ser incluídos os cenários aqui selecionados, cujo entendimento está sintetizado a seguir:

O que são imagens contemporâneas? São todas as imagens presentes nas linguagens impressas, visuais e audiovisuais. Por exemplo, imagens em outdoors, em capas de livro e revistas, charges nos jornais impressos ou eletrônicos, as imagens que nos chegam pelas telas da TV ou pelo computador. Imagens produzidas pelo homem nesta e em outras sociedades, mas que, na atualidade, chegam a caracterizar a nossa cultura como imagética (2005: 305). 
LANA DE SOUZA CAVALCANTI

Considera-se, então, os cenários aqui abordados como imagens culturais e advoga-se pelo seu uso em atividades de ensino, sobretudo por meio dos conteúdos geográficos, para orientar a relação do sujeito com essas imagens, resultando na produção de conhecimento amplo e crítico sobre ela e para além dela, na reflexão sobre seu conteúdo, sobre seu significado, contribuindo assim para a formação de conceitos que formam um sistema conceitual para compreender a cidade contemporânea no contexto especifico da América Latina. 


\section{Q Bibliografia}

》 Almeida, E. M. F. de. (2017). Acessibilidade urbana no ensino de Geografia: formação de conceitos de alunos do ensino médio em Iporá-Goiás. (Dissertação de Mestrado). Recuperado de https://repositorio.bc.ufg.br/tede/handle/tede/7828

" Araújo, M. P. (2017). Cidadania, segregação e desigualdades sociais: desafios e possibilidades da Geografia escolar em bairros periféricos da cidade de Goiânia-Go. (Dissertação de Mestrado). Goiânia: Programa de Pós-Graduação em GeografiaUniversidade Federal de Goiás, 2017. Recuperado de http://200.137.217.159/ index.php/component/jdownloads/category/63-2017?start=20

» Bento, I. P. (2011). Estudar a cidade e seus sujeitos para aprender Geografia. En: E. M. B. Morais y L. de S. Cavalcanti (Eds.). A cidade e seus sujeitos (pp.71-88). Goiânia: E. Vieira.

»Blanco, J., Bosoer, L. y Apaolaza, R. (2014). Movilidad, apropiación y uso del territorio: una aproximación a partir del caso de Buenos Aires. XIII Coloquio Internacional de Geocrítica El control del espacio y los espacios de control. Barcelona, 5-10 de mayo de 2014. Recuperado de http://www.ub.edu/geocrit/xiiicoloquio/xiii-coloquio-programa.htm

» Brum, J. L. S. (2017). Por uma interpretação humanista da relação entre lugar e mobilidade. Geousp-Espaço e Tempo, 21(1), 102-119.

"Carlos, A. F. A. (1996). O Lugar no/do mundo. São Paulo: Hucitec.

" Cavalcanti, L. de S. (2016). O olhar geográfico em formação: jovens estudantes de Geografia e desafios urbanos contemporâneos. En: F. M. de A. Paula, L. M. Pires y L. de S. Cavalcanti (Orgs.). Os jovens e suas espacialidades (pp. 121-142). Goiânia: Editora Espaço Acadêmico.

»Cavalcanti, L. de S. (2015). Jovens escolares e sua geografia: práticas espaciais e percepções no/do cotidiano da cidade. En: L. de S. Cavalcanti, E. Chaveiro y L. M. Pires (Orgs.) A cidade e seus jovens (pp. 13-30). Goiânia: Editora da PUC Goiás.

» Cavalcanti, L. de S. (2012). A geografia escolar e a cidade: ensaios sobre o ensino de Geografia para a vida urbana cotidiana. Campinas, São Paulo: Papirus.

»Cavalcanti, L. de S. (2011). Aprender sobre a cidade: a geografia urbana brasileira e a formação de jovens escolares. Revista Geográfica de América Central, Número Especial, 01-18.

"Corrêa, R. L. (2011). Sobre agentes sociais, escalas e produção do espaço urbano. En: A. F. A. Carlos, M. L. Souza y M. E. B. Spósito. A Produção do espaço Urbano (pp.41-52). São Paulo: Editora Contexto.

"Corrêa, R. L. (2013) Segregação Residencial: Classes Sociais e Espaço Urbano. En: P. de A. Vasconcelos, R. L. Corrêa y S. M. Pintaudi (Orgs). A cidade contemporânea: A segregação espacial (pp. 23-45). São Paulo: Contexto.

» Gomes, P. C. da C. (2013). O lugar do olhar. Rio de Janeiro: Bertrand Brasil.

» Hespanhol, R. Ap. de M. (2013). Campo e cidade, Rural e urbano no brasil contemporâneo. Mercator, 12(2), 103-112. 
LANA DE SOUZA CAVALCANTI

» Janoschka, M. (2016). Gentrificación, desplazamiento, desposesión: procesos urbanos claves en América Latina. Revista INVI, 31(88), 27-71.

» Jirón, P. y Mansilla P. (2014). Las consecuencias del urbanismo fragmentador en la vida cotidiana de habitantes de la ciudad de Santiago de Chile. EURE, 40(121), 5-28.

»Lefebvre, H. (2001). O direito à cidade. São Paulo: Centauro.

»Paula, F. M. de A. (2013). Jovens migrantes na metrópole de Goiânia: práticas espaciais, (re)territorializações e redes de sociabilidade. (Tese de Doutorado). Universidade Federal de Goiás. Recuperado de http://200.137.217.159/index.php/ component/jdownloads/category/7-2013?ltemid=-1

»Pinheiro, C. F. (2005). As imagens culturais na perspectiva vygotyskiana. Contrapontos, 5(2), Itajaí, mai./ago.

»Pires, L. M. (2013). Culturas geográficas de alunos-jovens: uma referência para a formação de professores de Geografia. (Tese de Doutorado). Goiânia: Programa de Pos-Graduação em Geografia - Universidade Federal de Goiás. Recuperado em http://200.137.217.159/index.php/component/jdownloads/category/72013 ?temid=-1

»Portela, M. O. B. (2017) 0 ensino de cidade na educação básica: conhecimento geográfico de jovens universitários em Teresina - Piauí. (Tese de Doutorado). Goiânia: Programa de Pós-graduação em Geografia - Universidade Federal de Goiás. Recuperado em http://200.137.217.159/index.php/component/ jdownloads/category/7-2013?ltemid=-1

"Silva, A. B. (2016). A geografia do espaço escolar: jovem-aluno, práticas espaciais e aprendizagem geográfica. (Tese de Doutorado). Goiânia: Programa de Pós-Graduação em Geografia. Universidade Federal de Goiás. Recuperado em http://200.137.217.159/index.php/component/jdownloads/category/72013 ?temid=-1

» Soja, E. W. (2014). Em busca de la justicia espacial. Valência, Espanha: Tirant Humanidades.

》Spironello, R. (2017). A relação Cidade/Campo no território goiano. Coleção Aprender a cidade, Goiânia, C\&A Alfa \& Comunicação.

» Da Redação. Jornal O Popular. (2017, 03 de setembro). Recuperado de https:// www.opopular.com.br/editorias/cidades/lojistas-da-regi\%C3\%A3o-da-rua-44protestam-contra-ambulantes-em-goi\%C3\%A2nia-1.1342239

»Évelin Argenta, Juliana Causin, Leopoldo Rosa e Vitor Gilard (04/09/2017). CBN Cultura. Recuperado de http://cbn.globoradio.globo.com/editorias/ cultura/2017/09/04/QUASE-100-ANOS-DEPOIS-PROJETO-PARA-CRIMINALIZARO-FUNK-REPETE-A-HISTORIA-DO-SAMBA.htm

Lana de Souza Cavalcanti / Is.cavalcanti17@gmail.com Licenciada em Geografia pela Universidade Federal de Goiás, Mestre em Educação pela Universidade Federal de Goiás, Doutora em Geografia Humana pela Universidade de São Paulo. Fez pós-doutoramento na Universidad Complutense de Madrid e na Universidade de Buenos Aires. Produz artigos, livros e capítulos de livros e pesquisa na área de ensino de Geografia, destacando-se as temáticas de Formação de Professores e ensino de cidade. Atualmente coordena o Núcleo de Estudos e Pesquisas em Ensino de Geografia - NEPEG e participa da Rede Latino-americana de investigadores da Didática da Geografia - Redladgeo. 